\title{
Does thromboprophylaxis prevent venous thromboembolism after major orthopedic surgery?*,**
}

\author{
A tromboprofilaxia evita o tromboembolismo venoso \\ após cirurgia ortopédica de grande porte?
}

\author{
Evrim Eylem Akpinar, Derya Hoşgün, Burak Akan, Can Ateş, Meral Gülhan
}

\begin{abstract}
Objective: Pulmonary embolism (PE) is an important complication of major orthopedic surgery. The aim of this study was to evaluate the incidence of venous thromboembolism (VTE) and factors influencing the development of VTE in patients undergoing major orthopedic surgery in a university hospital. Methods: Patients who underwent major orthopedic surgery (hip arthroplasty, knee arthroplasty, or femur fracture repair) between February of 2006 and June of 2012 were retrospectively included in the study. The incidences of PE and deep vein thrombosis (DVT) were evaluated, as were the factors influencing their development, such as type of operation, age, and comorbidities. Results: We reviewed the medical records of 1,306 patients. The proportions of knee arthroplasty, hip arthroplasty, and femur fracture repair were $63.4 \%, 29.9 \%$, and $6.7 \%$, respectively. The cumulative incidence of PE and DVT in patients undergoing major orthopedic surgery was $1.99 \%$ and $2.22 \%$, respectively. Most of the patients presented with PE and DVT (61.5\% and 72.4\%, respectively) within the first 72 $\mathrm{h}$ after surgery. Patients undergoing femur fracture repair, those aged $\geq 65$ years, and bedridden patients were at a higher risk for developing VTE. Conclusions: Our results show that VTE was a significant complication of major orthopedic surgery, despite the use of thromboprophylaxis. Clinicians should be aware of VTE, especially during the perioperative period and in bedridden, elderly patients ( $\geq 65$ years of age).
\end{abstract}

Keywords: Orthopedics; Pulmonary embolism; Venous thrombosis.

\section{Resumo}

Objetivo: A embolia pulmonar (EP) é uma complicação importante de cirurgia ortopédica de grande porte. Este estudo visou avaliar a incidência de tromboembolismo venoso (TEV) e os fatores que influenciam o desenvolvimento de TEV em pacientes submetidos a cirurgia ortopédica de grande porte em um hospital universitário. Métodos: Pacientes submetidos a cirurgia ortopédica de grande porte (artroplastia de quadril, artroplastia do joelho ou reparação de fratura de fêmur) entre fevereiro de 2006 e junho de 2012 foram incluídos retrospectivamente no estudo. As incidências de EP e de trombose venosa profunda (TVP) foram avaliadas, assim como os fatores que influenciaram sua ocorrência, tais como o tipo de cirurgia, idade e comorbidades. Resultados: Foram revisados os prontuários médicos de 1.306 pacientes. As proporções de artroplastia do joelho, artroplastia de quadril e reparação de fratura de fêmur foram, respectivamente, de 63,4\%, 29,9\% e 6,7\%. A incidência cumulativa de EP e TVP nos pacientes submetidos a cirurgia ortopédica de grande porte foi, respectivamente, de 1,99\% e $2,22 \%$. A maioria dos pacientes apresentou EP e TVP (61,5\% e 72,4 \%, respectivamente) nas primeiras $72 \mathrm{~h}$ após a cirurgia. Pacientes submetidos à reparação de fratura de fêmur, aqueles com idade $\geq 65$ anos, e pacientes acamados tinham um risco maior de desenvolver TVP. Conclusões: Nossos resultados demonstram que o TEV foi uma complicação importante de cirurgia ortopédica de grande porte, apesar da utilização de tromboprofilaxia. Os médicos clínicos devem estar alerta para a ocorrência de TEV, especialmente no período perioperatório e em pacientes idosos (com idade $\geq 65$ anos) e acamados.

Descritores: Ortopedia; Embolia pulmonar; Trombose venosa.

\footnotetext{
* Study carried out in the Department of Chest Diseases, Ufuk University, Ankara, Turkey.

Correspondence to: Evrim Eylem Akpinar. Chest Diseases Specialist Ufuk University Medical Faculty, Dr. Ridvan Ege Hospital, Department of Chest Diseases Mevlana Bulvari (Konya Yolu), 86-88, Balgat, 06540, Ankara, Turkey.

Tel. 90312 204-43-31. Fax: 90312 204-40-55. E-mail: drevrimeylem@gmail.com

Financial support: None.

Submitted: 20 December 2012. Accepted, after review: 14 March 2013.

**A versão completa em português deste artigo está disponível em www.jornaldepneumologia.com.br
} 


\section{Introduction}

Venous thromboembolism (VTE), specifically deep vein thrombosis (DVT) and pulmonary embolism (PE), is an important cause of morbidity and mortality. ${ }^{(1)}$ The risk of VTE is highest in patients undergoing major orthopedic surgery, particularly hip and knee arthroplasty. The American College of Chest Physicians (ACCP) guidelines recommend that each hospital implement strategies to identify the risk of VTE in medical and surgical patients in order to prevent morbidity and mortality due to this important clinical condition. ${ }^{(2)}$

Clinically significant bleeding occurs infrequently in patients who are taking an anticoagulant at a prophylactic dose. ${ }^{(3)}$ However, the risk of bleeding might limit the adequate use of anticoagulants in patients undergoing major orthopedic surgery. Because perioperative VTE is asymptomatic in the majority of the cases (95\%), this important clinical condition might be underestimated by surgeons, resulting in inadequate use of prophylactic anticoagulants. ${ }^{(4)}$

Not only is the use but also the duration of thromboprophylaxis important, especially for high-risk patients. In one meta-analysis, the incidence of symptomatic and fatal PE was found to be $3.2 \%$ and $0.1 \%$, respectively, in patients who had undergone hip or knee arthroplasty within a 3-month period and who had received short-term (7-10 days) thromboprophylaxis. ${ }^{(5)}$

In the present study, we evaluated the incidence of VTE and the factors influencing the development of VTE in patients undergoing major orthopedic surgery in a university hospital.

\section{Methods}

Between February of 2006 and June of 2012, all of the patients who had been referred to the Department of Orthopedics and Traumatology of the Ufuk University Hospital, located in the city of Ankara, Turkey, and submitted to surgery were retrospectively studied. The medical records of 7,580 patients were selected. The patients who underwent major orthopedic surgery (hip arthroplasty, knee arthroplasty, or femur fracture repair) were included in the study. The department had a standard protocol for thromboprophylaxis (enoxaparin $40 \mathrm{mg} /$ day s.c., and the use of graded compression stockings).This protocol was used during the period of the study.
The study was approved by the Research Ethics Committee of Ufuk University. The medical records of the patients were used in order to evaluate the incidence of DVT and PE within 45 postoperative days. Patients who underwent major orthopedic surgery in the hospital were routinely controlled on postoperative day 15,30 , and 45 . Patients who had respiratory symptoms (pleuritic chest pain, dyspnea, hemoptysis, or cough), with or without signs and symptoms consistent with DVT (swelling, pain, tenderness, increase in the diameter of lower limbs, or local heat), were evaluated by a pulmonologist. The patients suspected of having VTE were submitted to chest CT angiography and Doppler ultrasound of the lower extremities by an expert radiologist. Chest CT angiography was performed with a 16-section multidetector CT scanner (LightSpeed 16; GE Healthcare, Milwaukee, WI, USA) within 24 h. PE was diagnosed when an intraluminal filling defect surrounded by intravascular contrast or total occlusion of the pulmonary arterial lumen was detected at any level of the pulmonary arteries. Doppler ultrasound of the deep veins of the lower extremities was performed with a standard method using a dedicated ultrasound unit (LOGIQ 7; GE Healthcare) with a 10L linear array transducer (bandwidth, 6-10 MHz) in order to investigate the presence/absence of intravenous thrombi.

Data on the type of surgical procedure, the type and duration of anesthesia, and other potential risk factors for VTE, including obesity, immobility (bed rest $>48 \mathrm{~h}$ ), malignancy, previous history of VTE, COPD, congestive heart failure, trauma, thrombocytosis, and history of hormone replacement, were also recorded. In addition, the time of initiation and the duration of thromboprophylaxis were collected.

The data were analyzed using the Statistical Package for the Social Sciences for Windows, version 15.0 (SPSS Inc., Chicago, IL, USA). Descriptive statistical analysis results were presented as absolute and relative frequencies. Differences between groups for categorical variables were analyzed using the chi-square test or Fisher's exact test, where appropriate. The three clinically important variables among those which were found significantly effective in the development of VTE in the univariate analysis were evaluated by multiple logistic regression analysis in order to define independent risk factors of outcome variables. Adjusted odds ratios and respective 
95\% Cls were calculated. The level of statistical significance was set at $p<0.05$.

\section{Results}

The data of 1,306 patients were assessed. The mean age of the patients was $66.36 \pm 18.00$ years. Females and males accounted for $77.2 \%$ and $22.8 \%$, respectively. General anesthesia was administered to $18.8 \%$ of the patients, whereas $81.2 \%$ of the patients were treated with combined spinal-epidural anesthesia. The proportions of knee arthroplasty, hip arthroplasty, and femur fracture repair were $64.0 \%, 29.6 \%$, and $6.4 \%$, respectively. Of the 1,306 patients, 29 (2.22\%) and 26 (1.99\%), respectively, were diagnosed with DVT and PE.

All of the patients wore compression stockings and received VTE prophylaxis. Enoxaparin (40 $\mathrm{mg} /$ day) was the anticoagulant used for all of the patients, who received VTE prophylaxis during 30 postoperative days. Data related to demographics, type of surgical procedure, anesthesia, and type of thromboprophylaxis are shown in Table 1.

Prophylaxis was started at the tenth postoperative hour. Major bleeding (gastrointestinal bleeding) was reported in 1 patient (0.07\%) with a diagnosis of Crohn's disease. Nearly one-third of the patients (31.8\%) presented with one or more than one risk factor for VTE other than the orthopedic surgery. Additional risk factors for VTE are included in Table 2.

The incidence of symptomatic DVT and PE in the patients studied was $2.22 \%$ and $1.99 \%$, respectively. All of the patients with PE were also diagnosed with concomitant DVT. The incidences of PE following knee arthroplasty, hip arthroplasty, and femur fracture repair were $0.7 \%, 2.0 \%$ and $4.6 \%$, respectively.

Of the patients who had PE and DVT, 61.5\% and $72.4 \%$, respectively, developed them within the first 72 postoperative hours. The time for the onset of PE and DVT in the patients is shown in Table 3. In this sample of patients, $15.4 \%$ of the patients with PE died, creating a mortality rate of $0.3 \%$. Thrombolytic treatment was required in $15.4 \%$ of the patients with PE and was followed with standard heparin and warfarin treatment. Patients not receiving thrombolytic treatment were initially administered low-molecular-weight heparin (LMWH) and continued on warfarin therapy.
Table 1 - Demographic data, type of surgery, and type of anesthesia used in the patients included in the study $(\mathrm{n}=1,306)$. $^{\mathrm{a}}$

\begin{tabular}{lc}
\hline \multicolumn{1}{c}{ Variable } & Result \\
\hline Age, years & \\
Gender & $66.36 \pm 18.00$ \\
$\quad$ Male & $298(22.8)$ \\
$\quad$ Female & $1,008(77.2)$ \\
Type of surgery & \\
$\quad$ Knee arthroplasty & $836(64.0)$ \\
$\quad$ Hip arthroplasty & $387(29.6)$ \\
$\quad$ Femur fracture repair & $83(6.4)$ \\
Type of anesthesia & \\
$\quad$ General & $246(18.8)$ \\
$\quad$ Combined spinal-epidural & $1,060(81.2)$ \\
\hline
\end{tabular}

${ }^{a}$ Values expressed as $n(\%)$, except where otherwise indicated. ${ }^{b}$ Value expressed as mean \pm SD.

Table 2 - Distribution of potential risk factors other than major orthopedic surgery for pulmonary embolism. ${ }^{\mathrm{a}}$

\begin{tabular}{lc}
\hline \multicolumn{1}{c}{ Additional risk factor } & Study sample \\
\cline { 2 - 2 } & $(\mathrm{n}=1,306)$ \\
\hline Obesity & $59(4.5)$ \\
lmmobility & $197(15.1)$ \\
Malignancy & $10(0.8)$ \\
Previous history of VTE & $39(3.0)$ \\
COPD & $17(1.3)$ \\
Congestive heart failure & $60(4.6)$ \\
Trauma & $10(0.8)$ \\
Hormone replacement & $10(0.8)$ \\
Thrombocytosis & $8(0.6)$ \\
\hline
\end{tabular}

The majority of the patients (84.6\%) who developed PE were aged $\geq 65$ years $(p=0.004)$. No significant differences were found regarding the gender or the type of anesthesia administered in the group of patients who developed PE ( $p$ $>0.05$ ).

The multiple logistic regression analysis revealed that the patients undergoing femur fracture repair were at a greater risk for the development of PE than those who underwent knee or hip arthroplasty (OR $=4.413 ; 95 \% \mathrm{Cl}$ : $1.185-16.44 ; p=0.027)$. Patients aged $\geq 65$ years also had higher rates of $\mathrm{PE}(\mathrm{OR}=4.856$; 95\% Cl: $1.074-21.953 ; p=0.040)$. Table 4 shows the independent factors influencing the risk of developing PE.

The incidence of PE was higher in bedridden patients than in those who were not $(p=$ 0.004). However, the incidence of PE in obese 
Table 3 - Time for the onset of pulmonary embolism and deep vein thrombosis in the study sample.

\begin{tabular}{|c|c|c|}
\hline \multirow[t]{2}{*}{ Onset of PE, postoperative days } & \multicolumn{2}{|c|}{$\begin{array}{c}\text { Study sample } \\
(\mathrm{n}=1,306)\end{array}$} \\
\hline & $n$ & $\%$ \\
\hline 1 & 5 & 19.2 \\
\hline 2 & 9 & 34.6 \\
\hline 3 & 2 & 7.7 \\
\hline 4 & 1 & 3.8 \\
\hline 7 & 1 & 3.8 \\
\hline 15 & 4 & 15.4 \\
\hline 45 & 2 & 7.6 \\
\hline TOTAL & 26 & 100.0 \\
\hline \multicolumn{3}{|l|}{ Onset of DVT, postoperative days } \\
\hline 1 & 6 & 20.68 \\
\hline 2 & 10 & 34.48 \\
\hline 3 & 5 & 17.24 \\
\hline 4 & 1 & 3.44 \\
\hline 7 & 1 & 3.44 \\
\hline 15 & 4 & 13.79 \\
\hline 45 & 2 & 6.89 \\
\hline TOTAL & 29 & 100.0 \\
\hline
\end{tabular}

PE: pulmonary embolism; and DVT: deep vein thrombosis.

patients or in patients with a previous history of VTE, COPD, congestive heart failure, trauma, hormone replacement, or thrombocytosis was not significantly higher than in the other participants ( $p>0.05$ for all).

\section{Discussion}

The incidence of PE and DVT in the patients following major orthopedic surgery was 1.99\% and 2.22\%, respectively. Most of the patients developed PE or DVT within the first 72 postoperative hours. The patients undergoing femur fracture repair, those aged $\geq 65$ years, and those who were bedridden were at a higher risk for developing VTE.

In approximately 50\% of the patients undergoing major orthopedic surgery (knee or hip arthroplasty), DVT occurs in the proximal leg veins. ${ }^{(6)}$ Because these patients are at a high risk for VTE, thromboprophylaxis is routinely recommended by current guidelines. ${ }^{(2)}$

In one review, the rates of patients receiving prophylaxis after hip arthroplasty, knee arthroplasty, and femur fracture repair were reported as $84 \%$, $76 \%$, and $45 \%$, respectively. ${ }^{(7)}$ All of the patients undergoing major orthopedic surgery in the hospital under study received VTE prophylaxis. Femur fracture, which is a long bone fracture,
Table 4 - Factors influencing the development of pulmonary embolism in patients undergoing major orthopedic surgery.

\begin{tabular}{|c|c|c|c|}
\hline Factor & OR & $95 \% \mathrm{Cl}$ & $p$ \\
\hline \multicolumn{4}{|l|}{ Type of surgery } \\
\hline Knee arthroplasty & 1.00 & & \\
\hline Hip arthroplasty & 2.904 & $0.977-8.635$ & 0.055 \\
\hline $\begin{array}{l}\text { Femur fracture } \\
\text { repair }\end{array}$ & 4.413 & $1.185-16.440$ & 0.027 \\
\hline \multicolumn{4}{|l|}{ Age, years } \\
\hline$<65$ & 1.00 & & \\
\hline$\geq 65$ & 4.856 & $1.074-21.953$ & 0.040 \\
\hline Additional risk factor ${ }^{a}$ & 2.371 & $0.881-6.375$ & 0.087 \\
\hline
\end{tabular}

increases the risk for VTE. The surgery creates an additional risk for the development of VTE. It has been previously reported that VTE can develop following hip fracture surgery despite thromboprophylaxis. ${ }^{(8)}$ The incidence of PE was highest in the patients submitted to femur fracture repair (4.6\%) among the major orthopedic surgeries in our study population. This can be explained by the following factors: patients undergoing femur fracture repair are commonly older, and long bone fracture itself increases the risk for VTE due to prolonged immobility and increased endothelial injury.

It has been previously reported that the low incidence of symptomatic VTE perioperatively (5\%) might mislead surgeons into considering PE as a rare complication of major orthopedic surgeries..$^{(9,10)}$ On the contrary, the present study demonstrated that approximately $60 \%$ of symptomatic PE occurred within the first 72 postoperative hours, despite the routine use of prophylaxis. It is well known that damage to vascular endothelium and venous stasis resulting in endothelial hypoxia can cause the activation of the coagulation cascade. The natural fibrinolytic activity of the body tries to overcome the formation of thrombosis. ${ }^{(11)}$ The development of PE, more commonly within 3 days after surgery, might be due to the early intense effect of endothelial injury and hypoxia because of the surgical trauma and venous stasis.

Bleeding as a complication from medical prophylaxis is one of the factors that might lead to its inadequate use by the surgeons, especially following procedures such as a major orthopedic surgery. However, previous studies showed that 
the risk of clinically significant bleeding did not increase with medical prophylaxis. ${ }^{(3)}$ The incidence of major bleeding was very low in the present study $(0.07 \%)$, supporting the former data. Only 1 patient experienced major bleeding in the present study, and that patient had a prior diagnosis of Crohn's disease, which might have caused the bleeding.

In one study, the incidence of PE in patients who did not receive prophylaxis was approximately $50 \% .^{(10)}$ The use of prophylaxis decreased the incidence but did not completely resolve the problem. In one meta-analysis, it was reported that the incidence of PE within 3 months after the procedure was $3.2 \%$ in patients receiving short-term prophylaxis (7-10 days). ${ }^{(5)}$ The incidence of PE was lower in the present study than in that meta-analysis. This difference between the results might be explained by the long-term prophylaxis (30 days) and the short duration of the follow-up of the patients (45 postoperative days) in our study, in contrast to the results in the studies included in that meta-analysis.

Previous studies showed that the duration of prophylaxis reduced the risk of symptomatic DVT. ${ }^{(12,13)}$ However, despite the long-term use of thromboprophylaxis in our study population, the prevention of this important complication was not completely achieved. Enoxaparin was the anticoagulant therapy administered to the highrisk population for prophylaxis. The commonly used dose of the medication was $40 \mathrm{mg} /$ day $(4,000 \mathrm{IU})$ in all of the patients despite their weight. The recommended dose of LMWH for thromboprophylaxis is $>3,400 \mathrm{IU}$ in accordance with the ACCP guidelines, although weight-based dose adjustments of LMWHs might provide more effective prophylaxis. ACCP recommends longterm thromboprophylaxis (30-35 days) after major orthopedic surgery. ${ }^{(2)}$ When we retrospectively reviewed the $\mathrm{LMWH}$ dose in the protocol, we realized that the dose was consistent with the ACCP guidelines.

White et al. reported that the incidence of VTE after hip arthroplasty was higher than that of VTE after knee arthroplasty (2.8\% vs. $2.1 \%)$. $^{(14)}$ Our study showed a more striking difference between the incidence of PE following hip and knee arthroplasty $(2.0 \%$ vs. $0.7 \%)$. Similarly to previous data, ${ }^{(15,16)}$ the highest incidence of PE in the present study $(4.6 \%)$ occurred in the group undergoing femur fracture repair.
Shorr et al. found the incidence of PE after major orthopedic surgery in patients receiving enoxaparin to be $2.3 \% .{ }^{(17)}$ In the present study, the incidence of PE was found to be $1.99 \%$ in patients receiving enoxaparin for thromboprophylaxis. The shorter duration of prophylaxis in the study by Shorr et al. might explain the difference in the incidences of PE (3.9 days vs. 30 days). In another study, ${ }^{(18)}$ the incidence of PE after major orthopedic surgery was $1.47 \%$, which is similar to our result (1.99\%).

Patients undergoing major orthopedic surgery are generally older. Additional risk factors other than surgery, such as malignancy and immobility, might increase with age. It is known that patients aged $>40$ years are at a greater risk for VTE than younger patients and that prolonged immobility, together with other major risk factors, increases the risk for VTE. ${ }^{(10)}$ Similarly to previous studies, the present study showed that patients aged $\geq$ 65 years were at a significantly higher risk for PE after major orthopedic surgery. Immobility was also found to be one factor increasing the risk for VTE.

Although a previous history of VTE and obesity are known risk factors for VTE, ${ }^{(10)}$ these two conditions were not found to be independent risk factors for VTE in the present study. In our study, the previous history of VTE of patients might not have been adequately documented on the medical records.

For patients undergoing major orthopedic surgery, the latest ACCP guidelines ( $9^{\text {th }}$ edition) recommend extended pharmacological prophylaxis (up to 35 days) with LMWH or other anticoagulant medications rather than short-term prophylaxis. The guidelines also recommend that thromboprophylaxis should be started at least within the first 12 postoperative hours. ${ }^{(5)}$ The protocol of the hospital in the current study was consistent with the ACCP recommendations with regard to the method, duration, and time of initiation of thromboprophylaxis after major orthopedic surgery, and, as a result, only 1 patient developed PE after the continuation of the prophylactic treatment.

The present study had several limitations. First, because this was a retrospective study, the follow-up period of the patients after major orthopedic surgery was short (45 days), and only symptomatic VTE was evaluated. Second, the dose, the duration, and the type of medical 
prophylaxis used were the same to all of the patients.

Prospective randomized studies in which patients are followed for a longer period of time are necessary in order to evaluate the incidence of VTE more precisely, as well as to determine the optimum dose of medications for thromboprophylaxis and duration of the treatment following major orthopedic surgery.

In conclusion, the present study showed that VTE was an important complication of major orthopedic surgery, despite the use of compression stockings and pharmacological thromboprophylaxis with enoxaparin. Clinicians should be aware of VTE, especially during the perioperative period and in patients aged $\geq 65$ years.

\section{Acknowledgements}

The authors would like to express their appreciation to Dear Gulten Ortac for proofreading the manuscript.

\section{References}

1. White RH. The epidemiology of venous thromboembolism. Circulation. 2003;107(23 Suppl 1):14-8. http://dx.doi. org/10.1161/01.CIR.0000078468.11849.66

2. Guyatt GH, Akl EA, Crowther M, Gutterman DD, Schuünemann HJ; American College of Chest Physicians Antithrombotic Therapy and Prevention of Thrombosis Panel. Executive summary: Antithrombotic Therapy and Prevention of Thrombosis, 9th ed: American College of Chest Physicians Evidence-Based Clinical Practice Guidelines. Chest. 2012;141(2 Suppl):7S-47S. Erratum in: Chest. 2012;141(4):1129.

3. Geerts WH, Pineo GF, Heit JA, Bergqvist D, Lassen MR, Colwell CW, et al. Prevention of venous thromboembolism: the Seventh ACCP Conference on Antithrombotic and Thrombolytic Therapy. Chest. 2004;126(3 Suppl):338S400S. http://dx.doi.org/10.1378/chest.126.3_suppl.338S

4. Arcelus Jl, Caprini JA, Reyna JJ. Finding the right fit: effective thrombosis risk stratification in orthopedic patients. Orthopedics. 2000;23(6 Suppl):s633-8.

5. Douketis JD, Eikelboom JW, Quinlan DJ, Willan AR, Crowther MA. Short-duration prophylaxis against venous thromboembolism after total hip or knee replacement: a meta-analysis of prospective studies investigating symptomatic outcomes. Arch Intern Med. 2002;162(13):1465-71. http://dx.doi.org/10.1001/ archinte.162.13.1465

6. Nicolaides AN, Breddin HK, Fareed J, Goldhaber $\mathrm{S}$, Haas S, Hull R, et al. Prevention of venous thromboembolism. International Consensus Statement. Guidelines compiled in accordance with the scientific evidence. Int Angiol. 2001;20(1):1-37. http://dx.doi. org/10.1177/000331970105200101

7. Stratton MA, Anderson FA, Bussey HI, Caprini J, Comerota A, Haines ST, et al. Prevention of venous thromboembolism: adherence to the 1995 American College of Chest Physicians consensus guidelines for surgical patients. Arch Intern Med. 2000;160(3):334-40. http://dx.doi.org/10.1001/archinte.160.3.334

8. Deitelzweig SB, McKean SC, Amin AN, Brotman DJ, Jaffer AK, Spyropoulos AC. Prevention of venous thromboembolism in the orthopedic surgery patient. Cleve Clin J Med. 2008;75 Suppl 3:S27-36. http://dx.doi. org/10.3949/ccjm.75.Suppl_3.S27

9. Anderson FA Jr, Spencer FA. Risk factors for venous thromboembolism. Circulation. 2003;107(23 Suppl 1):19-16. http://dx.doi.org/10.1161/01.CIR.0000078469.07362.E6

10. Arcelus JI, Kudrna JC, Caprini JA. Venous thromboembolism following major orthopedic surgery: what is the risk after discharge? Orthopedics. 2006;29(6):506-16.

11. Enders JM, Burke JM, Dobesh PP. Prevention of venous thromboembolism in acute medical illness. Pharmacotherapy. 2002;22(12):1564-78. http://dx.doi. org/10.1592/phco.22.17.1564.34124

12. Hull RD, Pineo GF, Stein PD, Mah AF, Maclsaac SM, Dahl OE, et al. Extended out-of-hospital low-molecular-weight heparin prophylaxis against deep venous thrombosis in patients after elective hip arthroplasty: a systematic review. Ann Intern Med. 2001;135(10):858-69. http:// dx.doi.org/10.7326/0003-4819-135-10-200111200-00006

13. Eikelboom JW, Quinlan DJ, Douketis JD. Extendedduration prophylaxis against venous thromboembolism after total hip or knee replacement: a meta-analysis of the randomised trials. Lancet. 2001;358(9275):9-15. http://dx.doi.org/10.1016/S0140-6736(00)05249-1

14. White RH, Romano PS, Zhou H, Rodrigo J, Bargar W. Incidence and time course of thromboembolic outcomes following total hip or knee arthroplasty. Arch Intern Med. 1998;158(14):1525-31. http://dx.doi.org/10.1001/ archinte.158.14.1525

15. Edelsberg J, Ollendorf D, Oster G. Venous thromboembolism following major orthopedic surgery: review of epidemiology and economics. Am J Health Syst Pharm. 2001;58 Suppl 2:S4-13.

16. Gillespie W, Murray D, Gregg PJ, Warwick D. Risks and benefits of prophylaxis against venous thromboembolism in orthopaedic surgery. J Bone Joint Surg Br. 2000;82(4):475-9. http://dx.doi. org/10.1302/0301-620X.82B4.10452

17. Shorr AF, Kwong LM, Sarnes M, Happe L, Farrelly E, Mody-Patel N. Venous thromboembolism after orthopedic surgery: implications of the choice for prophylaxis. Thromb Res. 2007;121(1):17-24. http://dx.doi.org/10.1016/j. thromres.2007.02.013

18. Mraovic B, Hipszer BR, Epstein RH, Pequignot EC, Parvizi J, Joseph Jl. Preadmission hyperglycemia is an independent risk factor for in-hospital symptomatic pulmonary embolism after major orthopedic surgery. J Arthroplasty. 2010;25(1):64-70. http://dx.doi.org/10.1016/j. arth.2008.10.002 


\section{About the authors}

Evrim Eylem Akpinar

Physician. Department of Chest Diseases, Ufuk University, Ankara, Turkey.

\section{Derya Hoşgün}

Physician. Department of Chest Diseases, Ufuk University, Ankara, Turkey.

\section{Burak Akan}

Physician. Department of Orthopedics and Traumatology, Ufuk University, Ankara, Turkey.

\section{Can Ateş}

Physician. Department of Biostatistics, Ankara University, Ankara, Turkey.

\section{Meral Gülhan}

Chief. Department of Chest Diseases, Ufuk University, Ankara, Turkey. 